anically occlusive methods carry an assurance of no systemic side effects, while local reactions are extremely rare. The older woman nearing her 40 s who continues to take the oral contraceptives once her family is complete, or who by using a less efficient method risks an unwanted pregnancy, is exposing herself to an ever-increasing hazard. These are the women who may benefit most from a review initiated by the doctor: after counselling more and more couples are opting for sterilisation. ${ }^{9}$

${ }^{1}$ Bone, M, Family Planning Services in England and Wales-an Enquiry Carried out on Behalf of the Department of Health and Social Security. London, HMSO, 1973.

2 Kantner, J F, and Zelnik, M, Family Planning Perspectives, 1972, 4, No 4,9 .

3 McCance, C, and Hall, D J, British Medical fournal, 1972, 2, 694-700.

${ }^{4}$ Cole, J B, Beighton, F C L, and Jones, I H, British Medical fournal, 1975, 4, 217 .

5 Glass, R, Vessey, M, and Wiggins, P, Contraception, 1974, 10, 591.

6 Potts, M, and McDevitt, J, Contraception, 1975, 11, 701.

${ }^{7}$ Bone, M, Measures of Contraceptive Effectiveness and Their Uses. Studies on Medical and Population Subjects, No 28. London, HMSO, 1975.

8 Vessey, M, and Wiggins, P, Contraception, 1974, 9, 15.

9 Vessey, M, et al, fournal of Biosocial Science, 1976, 8, 373.

${ }^{10}$ Mann, J I, and Inman, W H W, British Medical fournal, 1975, 2, 245.

11 DHSS, Report on Confidential Enquiries into Maternal Deaths in England and Wales, 1970-1972. Reports on Health and Social Subjects No 11. London, HMSO, 1975.

12 Stolley, P D, et al, American fournal of Epidemiology, 1975, 102, 197.

13 British Medical fournal, 1976, 1, 545.

14 British Medical fournal, 1976, 2, 717.

15 Weström, L, Bengtsson, L P, and Mårdh, P, Lancet, 1976, 2, 221.

\section{Retinal vein occlusion}

Diseases of the retinal vascular system may severely interfere with visual function, and occlusion of the retinal vein forms one important cause of visual loss in Britain. ${ }^{1}$ The condition is uncommon below the age of 40 , but the incidence increases with age.

Retinal vein occlusions may be classified into central and branch (tributary) vein lesions. Occlusions of the central retinal vein show a wide range of appearances ranging from few intraretinal haemorrhages and dilated veins to extensive haemorrhages extending from the optic disc to the retinal periphery. In every case there is evidence of raised pressure in the central retinal vein, and in most cases venous opticociliary channels may be seen on the optic disc bypassing the site of the obstruction. The visual symptoms range from none whatsoever to profound visual loss of sudden onset. Opticociliary bypass channels may persist for years, and in the mild cases these may be the only residual signs of earlier central retinal vein occlusion. ${ }^{2}$

The outcome of an acute occlusion of the central retinal vein varies from near total recovery to a complete loss of function. Whether or not recovery occurs seems to be more directly related to retinal capillary damage with resulting anoxia than the extent of the haemorrhages when first seen. ${ }^{3}$ The most feared sequel is the development of thrombotic glaucoma, presenting acutely as a red painful eye within three months of the central vein occlusion; this occurs in $10-15 \%$ of cases.

Retinal branch vein occlusions effect one-half or less of the retina depending on the size of the occluded vessel. The area affected may be the upper or lower half of the retina. A quadrantic defect may be produced by an upper or lower temporal vein occlusion; or there may be a small tributary vein occlusion, either draining the macular region or the retinal periphery. Branch vein occlusions of tributaries drain- ing the macular region are associated with altered central vision. As with central vein occlusion, the branch vein obstructions lead to the development of bypass channels. When the macular region is affected the prognosis for vision depends on the degree to which capillary integrity is preserved: non-perfusion with retinal anoxia is related to poor visual recovery. ${ }^{4}$ The growth of new blood vessels from the retina and optic disc is a serious complication, for its development is related to lack of perfusion of the capillaries and the growth of new vessels may also cause visual loss from vitreous haemorrhage or retinal detachment.

Three groups of disorders predispose to retinal vein occlusion: haematological disease; disease of the vessel wall, as in the vasculitis associated with sarcoidosis and Behçet's disease; and pressure on the vein from without-from the adjacent retinal artery in central vein occlusion or at arteriovenous crossings in branch vein occlusion and in chronic simple glaucoma. Another aetiological factor may be increased blood viscosity. A recent large prospective controlled study ${ }^{5}$ in a group of patients with retinal vein occlusion found significantly higher blood and plasma viscosity in those patients with large areas of capillary damage and retinal anoxia, who would have a poorer visual prognosis. Arterial disease is a common accompaniment of retinal vein occlusion and until comparatively recently it was considered an important factor in its pathogenesis. Nevertheless, we now know that the arterial changes occur progressively after the occlusion rather than predating it, ${ }^{3}$ and experimental occlusion of the retinal veins in monkeys seems to confirm this view. ${ }^{6}$

Chronic glaucoma is sometimes associated with retinal vein occlusion, and the latter was found in $2 \%$ of a recent series of patients attending a glaucoma clinic. ${ }^{7}$ The site of obstruction may be on the optic disc, at the central retinal vein, or in one of its major tributaries draining the upper and lower half of the retina. The occlusion seems to be related to distortion of the retinal veins within the enlarged glaucomatous cup and the long-standing raised intraocular pressure.

The exact sequence of changes occurring at the site of obstruction is uncertain. Histological studies have failed to show that thrombosis is responsible; indeed, they suggest that the lumen is occluded by swelling of the endothelial cells and the tissues of the vein wall, apparently related to the adjacent retinal arteriole. ${ }^{8}$ It is unlikely that the vein lumen is totally occluded, but it seems probable from the persistence of bypass channels that the obstruction persists for a considerable time.

The variable visual outcomes of retinal vein occlusion make estimations of visual prognosis difficult and may have led to erroneous beliefs in the value of alternative forms of treatment. For that reason a recent prospective study of fluorescein angiography in assessing visual prognosis after central vein occlusion is to be welcomed. ${ }^{9}$ Vascular changes present one month after the initial episode were found to give a useful guide to prognosis. Retinal photocoagulation has been directed against retinal vessels considered likely to delay visual recovery or give rise to complications, or both. In retinal branch vein occlusions this technique has been useful in treating areas of retinal neovascularisation with the aim of limiting macular degeneration, vitreous haemorrhage, and retinal detachment. In central retinal vein occlusion it has been directed against areas of presumed retinal hypoxia in the hope of averting the onset of thrombotic glaucoma; as yet there is no conclusive evidence that photocoagulation alters the natural course of the disease.

Anticoagulants and fibrinolytic agents have also been tried. A truly randomised controlled trial of streptokinase in patients 
with central retinal vein thrombosis reported by Kohner and associates ${ }^{10}$ failed to detect any difference in the visual outcome. Nevertheless, the work of Ring and associates ${ }^{5}$ suggests that further evaluation might show that it has a role in treating this condition.

${ }^{1}$ Sorsby, A, The Incidence and Causes of Blindness in England and IV'ales 1963-68. London, HMSO, 1972

2 Wise, G N, Dollery, C T, and Henkind, P, The Retinal Circulation, chap 10. New York, Harper and Row, 1971.

${ }^{3}$ Kohner, E M, and Shilling, J S, in Medical Ophthalmology, chap 28, ed F C Rose. London, Chapman and Hall, 1976.

4 Clemmett, R S, Kohner, E M, and Hamilton, A M, Transactions of the Ophthalmological Societies of the United Kingdom, 1973, 93, 523.

${ }^{5}$ Ring, C P, et al, British fournal of Ophthalmology, 1976, 60, 397.

${ }^{6}$ Hamilton, A M, et al, Experimental Eye Research, 1975, 20, 493.

Hitchings, R A, and Spaeth, G L, British fournal of Ophthalmology, 1976, 60, 694 .

${ }^{8}$ Klien, B, American fournal of Ophthalmology, 1953, 36, 316.

${ }^{9}$ Laatikainen, L, and Kohner, E M, British Fournal of Ophthalmology, 1976, 60, 411.

10 Kohner, E M, et al, Transactions of the Ophthalmological Societies of the United Kingdom, 1974, 94, 599.

\section{Antibiotics for otitis media}

How to treat otitis media in children remains a subject of varied practice and controversy. The latest of a long series of admirably thorough American studies ${ }^{1}$ was based on 383 patients aged between 3 months and 5 years. Fluid obtained by needle aspiration of the middle ear was cultivated, often yielding pathogens only when the needle was washed out into broth. It grew pneumococci in $31 \%$ of cases, Haemophilus, mainly non-typable $H$ influenzae, in $22 \%$, both organisms in $5 \%$, and group A streptococci in 3\%. Four treatments were studied on a double-blind basis: amoxycillin, penicillin $\mathrm{V}$, erythromycin alone, and erythromycin combined with triple sulphapyrimidines. The best results were obtained with amoxycillin in both main types of infection, but in Haemophilus infections only the erythromycin-sulphonamide combination performed equally well; erythromycin alone and penicillin $\mathrm{V}$ were both less successful.

Observations included assays of the drugs in both blood and middle ear exudate in a few patients, and the in-vitro sensitivities of some of the strains were also determined to the three antibiotics. It seems from the table that the in-vitro tests were done not with penicillin $\mathrm{V}$ but with penicillin $\mathrm{G}$. If this was actually so it implies that the two penicillins were thought to have equivalent activity against $H$ influenzae. Clearly it should be recognised more widely that the activity of penicillin $\mathrm{G}$ against this organism exceeds that of $\mathrm{V}$ by fully fourfold. ${ }^{2}$ Phenoxypenicillins are all less active than benzyl penicillin against Gram-negative bacteria generally, with differences which among enterobacteria are even larger. ${ }^{3}$ Had these tests been done with penicillin $\mathrm{V}$, a reason for its poorer performance would have been apparent. On the other hand, Kamme $e t$ al $^{4}$ found that adequate doses of $\mathrm{V}$ could produce a level of $4 \mu \mathrm{g} / \mathrm{ml}$ in middle ear exudate, which is a concentration usually just inhibiting $H$ influenzae, and obtained satisfactory results with it.

The paper also reviewed earlier American work. A group at the Mayo Clinic ${ }^{5}$ compared Bicillin (a mixture of potassium, procaine, and benzathine penicillins) alone and combined with triple sulphonamides and with tetracycline in a series of 462 cases, much to the advantage of the two combinations. They $^{6}$ later repeated a comparison simply of Bicillin alone and with sulphonamides, the latter having previously given rather better results, and found little difference. Still earlier work had shown that sulphonamides alone are inferior to tetracycline, and, since tetracycline has been found inferior to penicillin, both can now be left out of account. Another group in Honolulu ${ }^{7}$ first compared ampicillin, penicillin and sulphafurazole, and oxytetracycline to the disadvantage of the last but with little to choose between the first two, and later ${ }^{8}$ penicillin $\mathrm{V}$ with and without sulphafurazole, erythromycin estolate, and ampicillin, and found all four treatments equally effective. In the wake of the 1973 papers one of the Mayo Clinic workers wrote an editorial ${ }^{9}$ asking how many more treatment trials were needed in otitis media. His conclusions were that penicillin is as good as any other antibiotic; that it can be given either intramuscularly or as tablets (on which point, as already stated, we disagree); that additional sulphonamides are unnecessary; and that the superiority of ampicillin over penicillin is unproved.

The difficulty which has been found in distinguishing between the merits of different antibiotic treatments can perhaps be explained by the fact that most cases resolve spontaneously. Only a little chemotherapeutic help may tip the balance in the patient's favour when the outcome is otherwise doubtful, and even if the drug is not the best choice it may still serve. Penicillins should be at the top of the list, and there is not much to choose between them for a pneumococcal or streptococcal infection. In the under-5s, however, $H$ influenzae is common and must be catered for. Here benzyl penicillin is more active than a phenoxypenicillin, though it is less convenient to administer; ampicillin more active than benzyl penicillin by a further fourfold difference; and amoxycillin, having the same activity as ampicillin but being much better absorbed, should (theoretically at least) be the most effective of all. Penicillin $\mathrm{V}$ appears the least promising, for it not only has a lower intrinsic activity but is also poorly absorbed and more highly proteinbound.

${ }^{1}$ Howard, J E, et al, American fournal of Diseases of Children, 1976, 130, 965.

2 Garrod, L P, British Medical fournal, 1960, 2, 1695.

${ }^{3}$ Barber, M, and Waterworth, P M, British Medical fournal, 1962, 1, 1159.

4 Kamme, C, Lundgren, K, and Rundcrantz, H, Scandinavian fournal of Infectious Diseases, 1969, 1, 77.

${ }^{5}$ Rubenstein, M M, et al, American Fournal of Diseases of Children, 1965, $109,308$.

${ }^{6}$ Stickler, G B, et al, American fournal of Diseases of Children, 1967, 114, 123.

'Bass, J W, et al, fournal of the American Medical Association, 1967, 202, 697.

${ }^{8}$ Bass, J W, et al, American Fournal of Diseases of Children, 1973, 125, 397.

${ }^{9}$ Stickler, G B, American fournal of Diseases of Children, 1973, 125, 403.

\section{Spontaneous pneumothorax}

Uncomplicated or benign spontaneous pneumothorax is a puzzling disorder usually affecting otherwise healthy young men. It was first differentiated from pneumothorax complicating tuberculosis by Kjaergaard, ${ }^{1}$ and studies in military personnel have suggested that its incidence is not declining. ${ }^{2}$ The greater incidence in males is unexplained, but the association with tall thin stature may arise because the mechanical stresses at the apex of the lung increase with lung height. ${ }^{3}$ Localised abnormalities may be found in the upper lobes, ${ }^{4}$ consisting of thin-walled cysts surrounded by fibrosis, collapse, and non-specific inflammation. In one recent study the edge of the posterior part of the first or second rib was 